\title{
Factors Influencing the Success of Shock Wave Lithotripsy Treatment for Urinary System Stone Disease in Children Aged 0-2
}

\author{
(1) Ibrahim Kartal1,2, (1) Mesut Altan2, (1) Burak Çıtamak2, (1) Emin Mammadov2, (1) Ali Cansu Bozacı², (1) Serdar Tekgül2 \\ ${ }^{1}$ Kütahya Health Science University Faculty of Medicine, Department of Urology, Kütahya, Turkiye \\ 2 Hacettepe University Faculty of Medicine, Department of Urology, Ankara, Turkiye
}

What's known on the subject? and What does the study add?

Shock wave lithotripsy (SWL) is a safe minimally invasive method that has been used for many years in the treatment of urinary system stone disease. It can also be used with high success and low morbidity in infants. In the presence of a single stone within the indications of SWL, higher success can be achieved with SWL in infants.

\begin{abstract}
Objective: Factors that may influence the efficiency and reliability of shock wave lithotripsy have been examined in the treatment of stone disease in patients aged 0-2.

Materials and Methods: The data of 149 patients treated with shock wave lithotripsy in our clinic between the ages of 0 and 2 years were evaluated retrospectively. Factors for predicting success in terms of overall stone-free rate were analyzed using univariate and multivariate analyses. Results: The mean age of the group was $14.39 \pm 4.56$ months. The stone-free status was achieved in $102(70.5 \%)$ patients in the first session, 15 $(65.2 \%)$ of 23 patients in the second session, and $2(50 \%)$ of 4 patients in the third session. Thus, $122(81.9 \%)$ of the children were stone-free after shock wave lithotripsy at an average of $10.01 \pm 11.34$ months of follow-up. The mean stone size was $8.66 \pm 3.47 \mathrm{~mm}$. Moreover, smaller stone size and single stones were found to be significant predictors of treatment success ( $p=0.007$ and $p \leq 0.001$, respectively). Additionally, it was determined that the single number of stones had a positive effect on treatment success in multivariable analysis (area under the curve $=0.683, p=0.002$ ). There were no major complications observed.

Conclusion: Our study has shown that shock wave lithotripsy can be used with high success and low morbidity in the treatment of urinary system stone disease in children aged 0-2, especially in the presence of a single stone.
\end{abstract}

Keywords: Urinary calculi, lithotripsy, infant, morbidity

\section{Introduction}

While the prevalence and characteristics of stone disease in children vary greatly depending on geographical factors, it is also influenced by environmental factors in the same way that other chronic diseases $(1,2)$. Given the delicate nature of childhood, urologists prefer minimally invasive methods for the treatment of pediatric urolithiasis. However, the use of shock wave lithotripsy (SWL) therapy, which is one of these alternatives, started with a delay in children, despite its widespread use in adults. The reason for this is the concern about potential adverse effects on the developing organ systems in children. However, subsequent studies have shown that the use of SWL in the treatment of kidney stones in children is a safe and effective method $(3,4)$.

When compared to adults, infants have a higher frequency of metabolic and anatomical anomalies, which affect the formation of stones and result in differences in treatment selection and treatment outcomes (5). Furthermore, their small anatomy and the fact that their modalities, such as percutaneous nephrolithotomy and retrograde intrarenal surgery, require long-term anesthesia, necessitate the development of even

Correspondence: İbrahim Kartal MD, Kütahya Health Science University Faculty of Medicine; Hacettepe University Faculty of Medicine, Department of Urology, Kütahya, Ankara, Turkiye Phone: +90 5556298424 E-mail: igk84@hotmail.com 0RCID-ID: orcid.org/0000-0002-2313-3522 Received: 08.05.2021 Accepted: 23.06 .2021

Cite this article as: Kartal I, Altan M, Çıtamak B, Mammadov E, Bozacı AC, Tekgül S. Factors Influencing the Success of Shock Wave Lithotripsy Treatment for Urinary System Stone Disease in Children Aged 0-2. J Urol Surg 2021;8(3):162-166.

๑Copyright 2021 by the Association of Urological Surgery / Journal of Urological Surgery published by Galenos Publishing House. 
more minimally invasive methods. Since the use of SWL on small groups, such as infants (0-23 months), raises concerns due to the anatomical factors, the number of studies on its application is limited. Therefore, the purpose of this study was to evaluate the efficacy and safety of using SWL in the treatment of pediatric urolithiasis in the $0-2$ age group, as well as the factors affecting the success of SWL.

\section{Materials and Methods}

In our study, we collected and analyzed data from 149 patients aged 0-2 who underwent SWL for urolithiasis in our clinic between January 2009 and September 2013. Patients with a history of cystine stones and cystinuria, as well as those with stones in more than one unit, were excluded from the study. Preoperatively, all patients were evaluated with kidney function tests, urinalysis, and urine culture.

Patients with urinary infections were underwent SWL after treated with antibiotherapy. In the first stage, ultrasonography \pm direct urinary system radiography was used for the diagnosis and treatment plan. In complex cases, unenhanced computed tomography (CT) was preferred as a last resort for diagnostic purposes. The stone size was accepted as the longest axis of the stone in the imaging method.

Stone fragmentation was performed under sedoanalgesia with the Siemens Lithostar Modularis ${ }^{\circledR}$ (Siemens AG, Munich, Germany) device under ultrasonographic guidance. Ultrasonography was used to assess the stone-free status of the patients 2 and 4 weeks after treatment. Further, no residue was approved as the criterion of treatment success. In the control examinations, if the fragmentations were insufficient and the patient was suitable for SWL indications, the SWL was repeated until the third session, at the earliest 2 weeks after the procedure. Factors that may affect the success of SWL in infants were evaluated using univariate and multivariate analyses.

\section{Statistical Analysis}

Statistical analyses were performed on SPSS 17.0. In the 0-2 age group, gender (female, male), side (right, left), degree of hydronephrosis (none to minimal, moderate to severe), number of stones (single, multiple), stone size $(\leq 10 \mathrm{~mm},>10 \mathrm{~mm})$, stone location (lower pole and off the lower pole), complaint (symptomatic, asymptomatic), and previous intervention (yes, no) parameters were evaluated, and their correlation with success was investigated using the chi-square test. The best predictive value for the stone size and age was determined using receiver operating characteristic (ROC) curve analysis. Using the logistic regression analysis, it was assessed whether these correlations were independent or not. A p-value of $\leq 0.05$ was regarded as significant.

\section{Results}

Table 1 shows the demographic information and clinical characteristics of the patients who took part in the study. The mean age of the 149 patients who underwent SWL between the ages of 0 and 2 was $14.39 \pm 4.56$ months. For a mean stone size of $8.66 \pm 3.47 \mathrm{~mm}, 89(60.9 \%)$ boys and 60 (31.1\%) girls were treated with SWL. One hundred thirty-five (90.6\%) of the patients had a single stone, with $22.1 \%$ of the stones located in the lower pole. While the most common complaint was pain and restlessness (40.2\%), moderate-to-severe hydronephrosis was detected in 31 (31.8\%) of the patients at their first appointment. The second session of SWL was conducted in 23 patients, and the third session of SWL was conducted in 4 patients in the patient group, with a median number of SWL sessions of 1 (13). While stone-free status was achieved in 105 (70.5\%) patients in the first session, it was achieved in 15 (65.2\%) of 23 patients in the second session and in $2(50 \%)$ of 4 patients in the third session. In general, with a mean stone burden of $8.66 \pm 3.47 \mathrm{~mm}$

Table 1. Demographic information and clinical characteristics of the patients in the study group

\begin{tabular}{|l|l|}
\hline Characteristics & $\mathbf{n}=\mathbf{1 4 9}$ \\
\hline Gender, $\mathrm{n}(\%)$ & \\
Male & $89(60.9)$ \\
Female & $60(31.1)$ \\
\hline Side, $\mathrm{n}(\%)$ & \\
Right & $76(51.1)$ \\
Left & $73(49.9)$ \\
\hline Age (months) (mean $\pm \mathrm{SD})$ & $14.39 \pm 4.56$ \\
\hline Hydronephrosis degree, $\mathrm{n}(\%)$ & \\
None-minimal & $118(79.2)$ \\
Moderate-severe & $31(31.8)$ \\
\hline Number of stones, $\mathrm{n}(\%)$ & \\
Single & $135(90.6)$ \\
Multiple & $14(10.4)$ \\
\hline Stone size, $\mathrm{n}(\%)$ & \\
$\leq 10$ mm & $125(83.9)$ \\
$>10$ mm & $24(16.1)$ \\
\hline Stone size (mm) (mean \pm SD) & $8.66 \pm 3.47$ \\
\hline Stone localization, $\mathrm{n}(\%)$ & \\
Upper pole & $20(13.4)$ \\
Middle pole & $45(30.2)$ \\
Lower pole & $33(22.1)$ \\
Renal pelvis & $39(26.2)$ \\
Ureter & $12(8.1)$ \\
\hline Complaint, $\mathrm{n}(\%)$ & \\
Pain-restlessness & $60(40.2)$ \\
Nausea-vomiting & $12(8.1)$ \\
Fever & $39(26.2)$ \\
Hematuria & $11(7.4)$ \\
Asymptomatic & $27(18.1)$ \\
\hline Previous intervention, $\mathrm{n}(\%)$ & $30(20.1)$ \\
\hline SD: Standard deviation & \\
\hline & \\
\hline & \\
\hline
\end{tabular}


during a mean follow-up of $10.01 \pm 11.34$ months, $122(81.9 \%)$ children in the patient group achieved stone-free status.

In a comparative analysis to determine the factors that may affect SWL treatment in children aged 0-2, it was determined that having a single stone $(p \leq 0.001)$ and a stone size smaller than $10 \mathrm{~mm}(p=0.007)$ were statistically significant factors for treatment success (Table 2). Following a multivariate analysis, it was discovered that having a single stone had a significant effect on success (odds ratio: 6.173, 95\% confidence interval: 1.189-20.946, $p=0.004$ ) (Table 3).

\begin{tabular}{|c|c|c|c|}
\hline Parameter (n) & $\begin{array}{l}\text { Stone-free } \\
\text { status } \\
\text { n (\%) }\end{array}$ & $\begin{array}{l}\text { Unsuccessful } \\
\text { n (\%) }\end{array}$ & $\mathbf{p}$ \\
\hline $\begin{array}{l}\text { Gender } \\
\text { Female (60) } \\
\text { Male (89) }\end{array}$ & $\begin{array}{l}46 \text { (76.7) } \\
76(85.4)\end{array}$ & $\begin{array}{l}14(23.3) \\
13(14.6)\end{array}$ & 0.393 \\
\hline $\begin{array}{l}\text { Side } \\
\text { Right (76) } \\
\text { Left (73) }\end{array}$ & $\begin{array}{l}60(78.9) \\
62(84.9)\end{array}$ & $\begin{array}{l}16(21.1) \\
11(15.1)\end{array}$ & 0.636 \\
\hline $\begin{array}{l}\text { Hydronephrosis grade } \\
\text { None-minimal (118) } \\
\text { Moderate-severe (31) }\end{array}$ & $\begin{array}{l}97(82.2) \\
25(80.6)\end{array}$ & $\begin{array}{l}21 \text { (17.8) } \\
6 \text { (19.4) }\end{array}$ & 0.932 \\
\hline $\begin{array}{l}\text { Number of stones } \\
\text { Single (135) } \\
\text { Multiple (14) }\end{array}$ & $\begin{array}{l}116(85.9) \\
6(42.9)\end{array}$ & $\begin{array}{l}19(14.1) \\
8(57.1)\end{array}$ & $<0.001^{*}$ \\
\hline $\begin{array}{l}\text { Stone size } \\
\leq 10 \mathrm{~mm}(125) \\
>10 \mathrm{~mm}(24)\end{array}$ & $\begin{array}{l}107(85.6) \\
15(62.5)\end{array}$ & $\begin{array}{l}18(14.4) \\
9(37.5)\end{array}$ & $0.007^{*}$ \\
\hline $\begin{array}{l}\text { Stone localization } \\
\text { Lower pole } \\
\text { Off the lower pole }\end{array}$ & $\begin{array}{l}27(81.3) \\
95(81.9)\end{array}$ & $\begin{array}{l}6(18.7) \\
21(18.2)\end{array}$ & 0.992 \\
\hline $\begin{array}{l}\text { Complaint } \\
\text { Symptomatic (122) } \\
\text { Asymptomatic (27) }\end{array}$ & $\begin{array}{l}99(81.1) \\
23(85.2)\end{array}$ & $\begin{array}{l}23 \text { (18.9) } \\
4(14.8)\end{array}$ & 0.622 \\
\hline $\begin{array}{l}\text { Presence of previous } \\
\text { intervention } \\
\text { Present (30) } \\
\text { Absent (119) }\end{array}$ & $\begin{array}{l}25(83.3) \\
97(81.5)\end{array}$ & $\begin{array}{l}5(16.7) \\
22(18.5)\end{array}$ & 0.223 \\
\hline Total (149) & $122(81.9)$ & $27(22.1)$ & - \\
\hline
\end{tabular}

Table 3. Multivariate analysis of the factors, which are found significant in univariate analysis, which can affect SWL treatment in infants

\begin{tabular}{|l|l|l|l|}
\hline & $\begin{array}{l}\text { Odds } \\
\text { ratio }\end{array}$ & $\begin{array}{l}\text { Confidence } \\
\text { interval }\end{array}$ & $\mathbf{p}$ \\
\hline $\begin{array}{l}\text { Number of stones } \\
\text { (single/multiple) }\end{array}$ & 6.173 & $1.189-20.946$ & 0.004 \\
\hline $\begin{array}{l}\text { Stone size } \\
(\leq 10 />10 \mathrm{~mm})\end{array}$ & 2.358 & $0.812-6.846$ & 0.115 \\
\hline $\begin{array}{l}\text { SWL: Shock wave lithotripsy } \\
{ }^{*} \mathrm{p} \leq 0.05\end{array}$ & \multicolumn{3}{|l}{} \\
\hline
\end{tabular}

In the patient group, it was determined that $1.31 \pm 0.26 \mathrm{~J}$ of average power was applied in the SWL procedure, with an average number of shocks of $1.629 \pm 269$. The best predictive value of stone size in SWL in the $0-2$ age group was found to be $10 \mathrm{~mm}$ in the ROC analysis (area under the curve $=0.683$, $p=0.002$ ) (Figure 1).

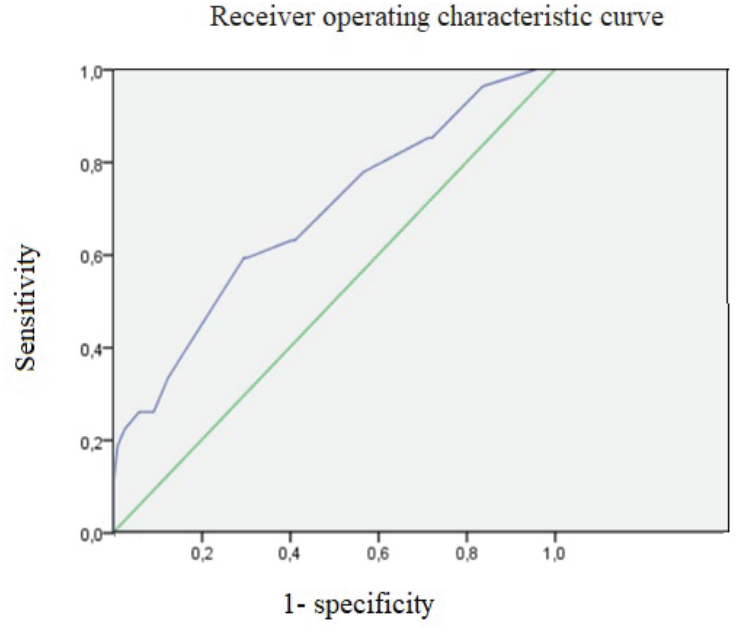

Figure 1. Cut-off value of ROC analysis for stone size in 0-2 age group ROC: Receiver operating characteristic

To evaluate the effect of age on success in stone fragmentation, the study group's successful and unsuccessful groups were compared. The average age was found to be $14.25 \pm 4.469$ months in the successful group, whereas it was $15.04 \pm 5.004$ in the unsuccessful group. It was found that age was not statistically significant among the groups in SWL success $(p=0.304)$. Furthermore, ROC analysis did not yield a significant predictive value.

When the patient group was evaluated in terms of complications, seven patients had ureteral stents placed after SWL due to stone tract. One patient was admitted to the hospital with a febrile urinary tract infection and was treated with antibiotherapy. There were no major complications during the perioperative period. During the follow-up period, no patients developed hypertension or proteinuria.

\section{Discussion}

According to the findings of our study, the use of SWL in infants with urinary system stone disease appears to be effective and safety. The high success and low morbidity rates of SWL treatment should not be overlooked in the treatment of urolithiasis, which has increased in recent years as a result of earlier diagnosis in childhood and the impact of evolving health systems.

Today, concerns about SWL damaging immature kidney and bone tissue are no longer valid. Studies based on animal 
experiments and long-term extensive patient experiences have revealed that kidney development and function did not change significantly following SWL $(6,7)$. It has also been proved that the success rate of SWL in children is comparable to that of adults. Some studies show that SWL is more effective in children than in adults, with stone-free state rates ranging from $60 \%$ to nearly $100 \%$ in various studies $(8,9)$. Aside from its success, the main advantages of SWL for younger patients are that it does not require long-term anesthesia like other surgical methods and can be performed with short-term sedoanalgesia.

The physical characteristics of this patient group in the early stages of childhood, the prevalence of anatomical anomalies, and the elevated metabolic risk factors make urolithiasis treatment challenging. Despite the fact that the number of studies is limited, high success rates for the treatment of SWL in infants have been identified. Younesi Rostami et al. (10) reported in their study in 2011 that they provided 100\% stone-free status in infants with SWL. The high success rate was attributed to the fact that the transmission of shock waves was higher in infants due to their small body surface (10). Moreover, Turna et al. (11) reported that they achieved high stone-free state rates with SWL in infants, and they did not observe the occurrence of hypertension or diabetes in either of the patients during their midterm follow-up, implying that SWL can be used safely and successfully in infants. In parallel with these studies, our study supports that SWL can be used successfully in the 0-2 age group with a relatively higher number of patients, compared to the previous studies with a limited number of patients.

Estimating which patients will benefit from it and how much they will benefit from it is just as critical as choosing a treatment method. Generally, as the number of stones increases, the treatment becomes more difficult, necessitating more invasive procedures. In our study, patients with a single stone in the 0-2 age group benefited more from the treatment than those with multiple stones. Contrarily, the number of stones was statistically proven to be the main factor influencing SWL success. In their study, Tan et al. (12) reported that an improvement in the number of stones was detrimental to the success of SWL treatment in patients under the age of 16 . The same argument holds true for children aged $0-2$, a subset of pediatric patients.

According to common perception, stone size has a negative effect on stone-free status in children, similar to adults. Thus, Onal et al. (13) reported that stone size has a negative effect on the success of SWL in children in their studies with a large patient series. However, on the contrary, Ather and Noor (14) also discovered in their studies that size has no effect on the success of SWL in stones up to $30 \mathrm{~mm}$. In our study, while the stone size was found to be effective in the success of SWL in univariate analysis, in multivariate analysis, similar to the study of Ather and Noor (14), the size factor did not affect infants. Nevertheless, due to the early diagnosis and small anatomy of the kidneys in infants, the smaller stone size may be efficient in reaching this outcome.

There have been few studies on the positive effect of age on SWL. Lottmann et al. (15) reported the stone-free rate in SWL as $87.5 \%$ in 16 infants and $71.4 \%$ in 7 patients aged $6-11$ years, emphasizing the positive effect of age on SWL. SWL has been shown to be more effective at younger ages in a few other studies (9). This could be because the skin-stone distance in pediatric patients is shorter than in adults. However, in comparison to other studies, our study group is more homogeneous in terms of age. In other studies, the age factor is evaluated by years, but in our study, the age factor was evaluated in months, which could affect the outcome.

The evaluation of metabolic factors is a crucial step in the general principle of treatment of stone disease. Patients with metabolic abnormalities, such as cystinuria, have a lower success rate of SWL (16). It is obvious that the patient's metabolic condition and stone type should be considered when planning treatment (17). Since our clinic is a referral center and some patients live a long distance away, we were unable to obtain metabolic and stone analysis data from all patients, and these results were not be included in the assessment.

Aside from its high success rate, SWL appears to be a method that can be used safety in the early stages of childhood in terms of complications and side effects. More serious complications, even though they are rare, have been reported in the literature for the use of SWL in infants. In our study, no major complications were observed in the short term in the 0-2 age group. Lu et al. (8) reported a $6 \%$ incidence of the stone tract after the use of SWL in infants in their meta-analysis. They concluded in their meta-analysis that SWL preference in children can be made without regard for the possibility of complications. However, due to the patient group's features, procedures such as retrograde intrarenal surgery, percutaneous nephrolithotomy, and open surgery may be required due to complications, and further treatment may be very difficult to implement in infants (18). Therefore, SWL procedures in the 0-2 age group should be performed in experienced clinics that are equipped to handle any complications that may arise.

While SWL is a minimally invasive method, the potential longterm consequences of SWL in groups vulnerable to environmental factors, such as early childhood, should be considered. Longterm complications, such as hypertension, diabetes, and proteinuria, were not observed in any of our patients, despite our short follow-up period. Many studies have already revealed that SWL has no chronic effects, even with meta-analyses $(7,19)$. However, knowledge on the usage of SWL in young children 
is only beginning to grow. Due to the recurrent nature of the stone disease, these patients should be closely monitored and their metabolism thoroughly investigated. In terms of patient follow-up and general health profiles, developing modern and informatics-based applications is still very important, similar to the follow-up of other chronic patients, given the circumstances of our age (20).

\section{Study Limitations}

Our study has some limitations. Primarily, the study is retrospective and does not include long-term results. Furthermore, since our clinic serves as a reference center, the results of metabolic and stone analyses could not be compiled entirely. However, given the importance of the management of stone disease in infants, we believe that our study can serve as a model for future research. While not using $\mathrm{CT}$, which is the most sensitive tool for assessing stone-free status, may be considered a limitation, due to its radioactive effects, tomography cannot be used in all patients in this age group.

\section{Conclusion}

SWL is an important treatment option with high success and low complication rates for infants with stone disease. The only independent factor affecting the success of SWL is the number of stones.

\section{Ethics}

Ethics Committee Approval: All procedures performed in studies involving human participants were in accordance with the ethical standards of the institutional and/or national research committee and with the 1964 Helsinki Declaration and its later amendments or comparable ethical standards. No ethics committee approval was sought for this study because of its retrospective and observational nature.

Informed Consent: Retrospective study.

Peer-review: Internally peer-reviewed.

\section{Authorship Contributions}

Surgical and Medical Practices: I.K., M.A., B.Ç., E.M., A.C.B., S.T., Concept: I.K., M.A., B.Ç., S.T., Design: I..K., M.A., B.Ç., S.T., Data Collection or Processing: i.K., M.A., B.Ç., E.M., A.C.B., Analysis or Interpretation: I.K., M.A., Literature Search: I.K, B.Ç., E.M., A.C.B., Writing: I.K., S.T.

Conflict of Interest: No conflict of interest was declared by the authors.

Financial Disclosure: The authors declare that they have no relevant financial.

\section{References}

1. Narter F, Narter F, Sarıca K. Urinary Stones in Neonates: Dilemma Between Urolithiasis and Nephrocalcinosis. Journal of Urological Surgery 2015;1:1-6.

2. Bartosh SM. Medical management of pediatric stone disease. Urol Clin North Am 2004;31:575-587.

3. Myers DA, Mobley TB, Jenkins JM, Grine WB, Jordan WR. Pediatric low energy lithotripsy with the Lithostar. J Urol 1995;153:453-457.

4. Brad $A B$, Ferro $M$, Vartolomei MD, Tătaru $S$, Anton-Păduraru DT, Simion C, Martha 0, Pricop C, Porreca A, Negru I. Particularities and Efficacy of Extracorporeal Shock Wave Lithotripsy in Children. Urol Int 2019;103:318325.

5. Coward RJ, Peters CJ, Duffy PG, Corry D, Kellett MJ, Choong S, van't Hoff WG. Epidemiology of paediatric renal stone disease in the UK. Arch Dis Child 2003;88:962-965.

6. Sarıkaya S, Karşıyakalı N, Sicimli C, Kaya E, Ebiloğlu T, Bedir S, Özgürtaş T, Karataş ÖF. Retrograde Intrarenal Surgery or Shock Wave Lithotripsy?: Comparison of the Effects on Renal Functions by Glomerular Filtration Rate. Journal of Urological Surgery 2019;6:295-301.

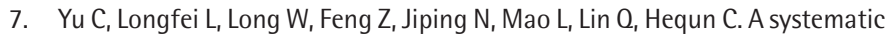
review and meta-analysis of new onset hypertension after extracorporeal shock wave lithotripsy. Int Urol Nephrol 2014;46:719-725.

8. Lu P, Wang Z, Song R, Wang X, Qi K, Dai Q, Zhang W, Gu M. The clinical efficacy of extracorporeal shock wave lithotripsy in pediatric urolithiasis: a systematic review and meta-analysis. Urolithiasis 2015;43:199-206.

9. Göktaş C, Akça O, Horuz R, Gökhan O, Albayrak S, Sarica K. Does child's age affect interval to stone-free status after SWL? A critical analysis. Urology 2012;79:1138-1142

10. Younesi Rostami M, Taghipour-Gorgikolai M, Sharifian R. Treatment of Kidney Stones Using Extracorporeal Shock Wave Lithotripsy (ESWL) and Double-J Stent in Infants. Adv Urol 2012;2012:589038.

11. Turna B, Tekin A, Yağmur I, Nazlı O. Extracorporeal shock wave lithotripsy in infants less than 12-month old. Urolithiasis 2016;44:435-440.

12. Tan MO, Kirac M, Onaran M, Karaoglan U, Deniz N, Bozkirli I. Factors affecting the success rate of extracorporeal shock wave lithotripsy for renal calculi in children. Urol Res 2006;34:215-221.

13. Onal B, Tansu N, Demirkesen O, Yalcin V, Huang L, Nguyen HT, Cilento BG, Erozenci $A$. Nomogram and scoring system for predicting stone-free status after extracorporeal shock wave lithotripsy in children with urolithiasis. BJU Int 2013;111:344-352.

14. Ather MH, Noor MA. Does size and site matter for renal stones up to $30-\mathrm{mm}$ in size in children treated by extracorporeal lithotripsy? Urology 2003;61:212-215

15. Lottmann HB, Traxer O, Archambaud F, Mercier-Pageyral B. Monotherapy extracorporeal shock wave lithotripsy for the treatment of staghorn calculi in children. J Urol 2001;165:2324-2327.

16. Landau EH, Shenfeld OZ, Pode D, Shapiro A, Meretyk S, Katz G, Katz R Duvdevani M, Hardak B, Cipele H, Hidas G, Yutkin V, Gofrit ON. Extracorporeal shock wave lithotripsy in prepubertal children: 22-year experience at a single institution with a single lithotriptor. J Urol 2009;182(4 Suppl):1835-1839.

17. Eyre KS, Lewis F, Cui H, Grout E, Mihai R, Turney BW, Howles SA. Utility of blood tests in screening for metabolic disorders in kidney stone disease. BJU Int 2021;127:538-543.

18. Tejwani R, Wang HH, Wolf S, Wiener JS, Routh JC. Outcomes of Shock Wave Lithotripsy and Ureteroscopy for Treatment of Pediatric Urolithiasis. J Urol 2016;196:196-201.

19. Fankhauser CD, Kranzbühler B, Poyet C, Hermanns T, Sulser T, Steurer J. Long-term Adverse Effects of Extracorporeal Shock-wave Lithotripsy for Nephrolithiasis and Ureterolithiasis: A Systematic Review. Urology 2015;85:991-1006.

20. Castaneda P, Ellimoottil C. Current use of telehealth in urology: a review. World J Urol 2020;38:2377-2384 